\title{
Molecular Cloning, Expression and Purification of Recombinant VHH Proteins Expressed in E. coli
}

\author{
Tewodros Fentahun Jember \\ Department of Biomedical Sciences, College of Veterinary Medicine and Animal Sciences, University of Gondar, Gondar, Ethiopia \\ Email: tedyvet@gmail.com
}

How to cite this paper: Jember, T.F. (2021) Molecular Cloning, Expression and Purification of Recombinant VHH Proteins Expressed in E. coli. American Journal of Molecular Biology, 11, 129-141.

https://doi.org/10.4236/ajmb.2021.114011

Received: November 11, 2020

Accepted: October 12, 2021

Published: October 15, 2021

Copyright $\odot 2021$ by author(s) and Scientific Research Publishing Inc. This work is licensed under the Creative Commons Attribution International License (CC BY 4.0).

http://creativecommons.org/licenses/by/4.0/

\begin{abstract}
Variable Heavy-chain Homodimer (VHH) or Nanobody is a recombinant dromedary antibody fragment which is classified as the smallest antibody fragments with the highest binding affinity and specificity of the original whole antibody. In this study the Expression of Nanobodies in E. coli WK6 cell periplasm was performed. The protein expression and purity was and analyzed by Affinity Chromatography, SDS PAGE and Western Blot. Upon elution with Imidazole, the concentrations observed using the $\mathrm{OD}_{280} \mathrm{~nm}$ of the eluted fractions EI, E2 and E3 were observed to be $0.42 \mu \mathrm{g} / \mathrm{ml}, 0.13 \mu \mathrm{g} / \mathrm{ml}$ and -0.46 $\mu \mathrm{g} / \mathrm{ml}$ respectively. This gives an Antilog of $7.88 \mathrm{kDa}$ which showed the calculated molecular size of our band. The SDS-PAGE gel reading was confirmed using Western blot analysis and illustrated as the specific binding of the mouse Anti-His antibody to the Histidine tag of the Nanobody. The Nanobody protein expression was then analyzed further with western blotting showed a strong signal at the region corresponding to the $15 \mathrm{kDa}$ marker indicating presence of the Nanobody gene. This was taken as further confirmation of the protein expression from the bacterial cells.
\end{abstract}

\section{Keywords}

VHH, Nanobody, Protein

\section{Introduction}

Nanobodies (VHHs) represent the heavy-chain variable domain of IgG2 and IgG3 expressed in Camelidae without the $\mathrm{CH} 1$ domain as well as of the light chain. It is assumed as one of the smallest antibody fragments with $14 \mathrm{kDa}$. It has significantly the highest binding affinity and specificity compared to the common whole antibody. It has a remarkable structural stability and easier mo- 
lecularly engineered structure which is convenient for both in vitro and in vivo applications as indicated in Figure 1 [1].

Generating the molecular clone of a gene can lead to the development of organisms that produce the protein product of the cloned genes, termed a recombinant protein. Recombinant protein expression technology has enabled expression of any gene-specific sequence of nucleotides present in animals, bacteria or humans. Through transcription and translation of those specific nucleotides in a suitable recombinant host cell, the desired protein can be expressed, extracted and purified. Practically, some concerns emerge when considering the expression of a recombinant protein. It is frequently easier to clone a gene than to produce it recombinantly. This is due to the complexity and variability of molecular signals for gene expression as well as the proper folding of the protein, its stability and transport. These factors make it difficult to develop an organism that produces an active form of a recombinant protein in desirable quantities.

Of the many protein expression systems available for recombinant protein production, the Gram negative bacterium Escherichia coli (E. coli) remains one of the most widely used. This bacterial system is inexpensive to grow, grows rapidly, has been well characterized and offers an ever increasing panoply of cloning vectors and mutant host strains [2] [3]. The techniques for over-expression in $E$. coli have been also been well developed and characterized. They work by either increasing the number of copies of the gene or increasing the binding strength of the promoter region so as to assist transcription [2].

The foreign DNA is normally introduced into the cell in a plasmid expression vector. The expression plasmid is also another important component in recombinant protein expression. The plasmid is a circular DNA present naturally in most bacteria; its value derives from its unique ability for self-replication and from the selection of a specific genotype after ligation with the foreign DNA. In particular, the pHEN6(C) plasmid is a genetically engineered plasmid designed to carry certain components for enabling successful expression of the Nanobody gene [4] [5] [6].

An important component of pHEN6(C) is that it contains a multiple cloning site (MCS) for the action of restriction enzymes. The pHEN6(C) MCS contains sites for HindIII, BstEII and EcoR1 which enable restriction digestion to generate "sticky ends" and eventually ligation of a suitably restriction digested gene. Another important component of pHEN6(C) is that it contains an Ampicillin resistance (ampere) gene, which enables antibiotic resistance driven selection for successfully transformed colonies from naive bacteria. The pHEN6(C) also contains an origin of replication (ori) that enables the plasmid to replicate independently of the bacterial chromosome to maintain itself, and hence the recombinant gene it possesses, in the bacterial population. Additionally the plasmid contains a LacZ promoter, an inducible control mechanism for the transcription of the genes contained downstream of it. Induction of recombinant gene expression can be stimulated chemically by using $\beta$-D-1-thiogalactopyranoside (IPTG). The plasmid also possesses a PelB signal which, when translated enables the 


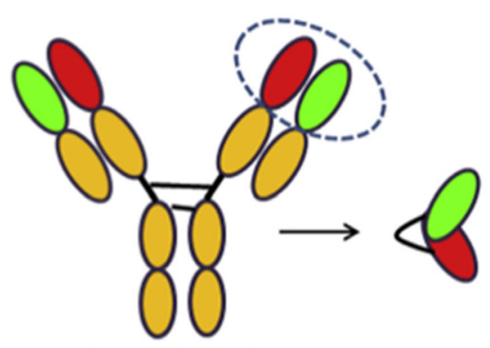

Conventional IgG

$\mathrm{scFV}$
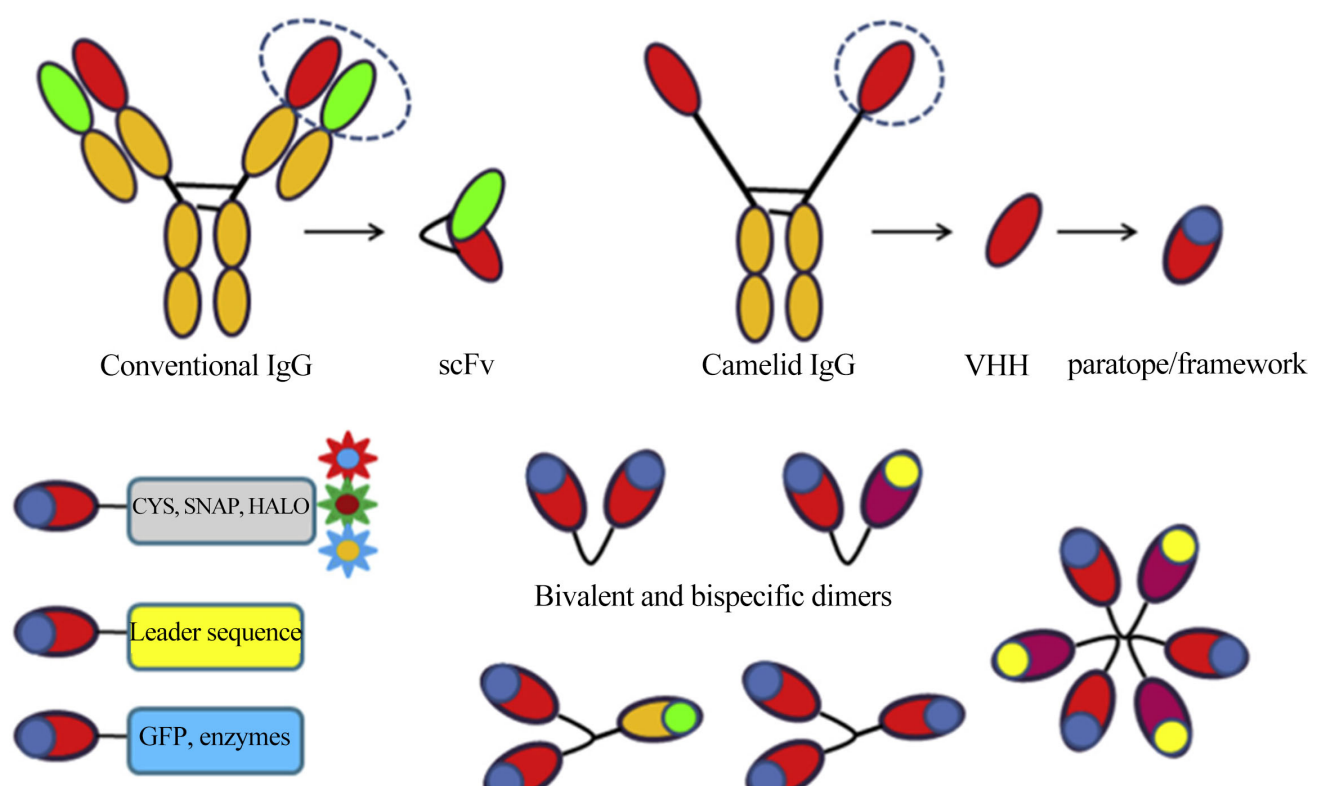

Bivalent and bispecific dimers
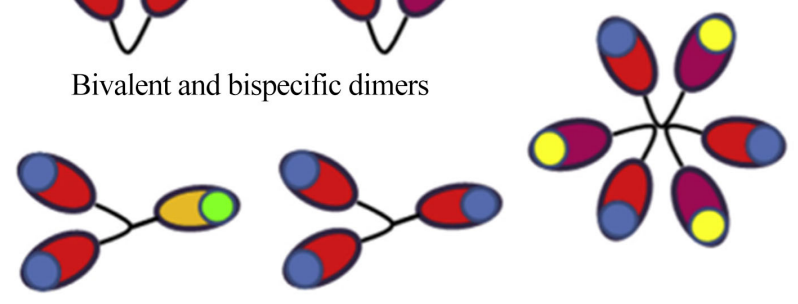

Homo- and hetero-polymers

Figure 1. Characteristics of nanobodies and nanobody construct [14].

transport of the expressed recombinant protein to the periplasmic space for proper folding to occur. In addition to this, there is encoded at the future C-terminal of the protein, a hexahistidine tag. The messenger RNA (mRNA) produced from transcription is translated using the ribosomal machinery provided by the host cell to express the recombinant gene. Once the recombinant protein is expressed in the periplasmic space, osmotic shock is performed to extract the nanobody protein out of the periplasmic space. After protein is extracted, it must be purified from the rest of the bacterial cellular protein [5] [6].

Immobilized metal-affinity chromatography (IMAC) is an alternative to classical separation techniques that can be employed for the purification of a recombinant protein [7]. Other alternatives exist, such as the glutathione S-transferase (GST) fusion system used together with glutathione-Sepharose beads, the protein a fusion system and the epitope tagging technique [7]. These techniques make use of a particular property of a protein moiety or short amino acid sequence fused to the recombinant protein as a "tag". Such a "tag" used can be the hex-histidinesequence present at the C-terminal end of the recombinant Nanobodies [8] [9]. Using slurry of negatively charged nickel beads, an array of the positively charged hexa-histidine tail of a recombinant protein is selectively bound to the column. The recombinant protein is then eluted using an imidazole buffer. Elution changes the $\mathrm{pH}$ properties under which the protein is bound to the nickel column, thus enabling its collection as relatively pure protein.

After protein expression, extraction and purification, analysis is performed to ascertain its molecular weight and qualitatively determine its presence. This can be carried out via Sodium dodecyl sulfate polyacrylamide gel electrophoresis (SDS-PAGE). SDS, an anionic detergent, disrupts the proteins folding by bind- 
ing to hydrophobic regions, causing the protein to denature and become monomeric [10]. It also oblates any differences in charge on the protein, proffering onto it a net negative charge [10]. Once denatured, the protein molecules are run through the gel with electric current, with the negatively charged protein molecules migrating towards the positive pole. As they are all negatively charged and denatured, depending on their individual molecular weights, each protein will migrate a specific distance towards the positive pole. A standard curve of proteins with known molecular weight can then be used to determine the molecular weight of the recombinant protein.

Visualization and hence confirmation of protein expression after separation can be undertaken by using the specific Coomasie blue staining technique or western blot. The Coomasie brilliant blue dye molecules bind to proteins to form a protein-dye complex [11]. The formation of the complex stabilizes the negatively charged anionic form of the dye producing the blue color. The dye also forms a complex with SDS [12]. The formation of this complex stabilizes the neutral green form of the dye.

Western blotting is also used to confirm the expression. This technique is based upon the hybridization of a protein/s to a nitrocellulose membrane, coupled to the immune-detection of these proteins [13]. Using a primary antibody which binds selectively to the protein of interest, secondary antibodies are added that bind to the first antibody. The secondary antibodies are coupled to an enzyme, which consumes a substrate upon addition, yielding a color which stains the membrane, indicating successful primary and secondary binding and therefore detection of the protein of interest.

In this study, we used E.coliWK6 cells, transformed with pHEN6(C) plasmid containing the VHH (Nanobody). The recombinant nanobody was expressed from the cell by induction with IPTG and osmotic rupture with TES. The recombinant nanobody protein was purified via the IMAC utilizing nickel ions to bind selectively the Hexahistidine tag of the nanobodies. The purified protein was then analyzed via SDS-PAGE and western blot.

\section{Materials and Methods}

The materials, chemicals and reagents required for the lab are listed as follows in three (3) columns:

\begin{tabular}{lll}
\hline - Sodium hypochlorite (disinfectant) & • Distilled Water $\left(\mathrm{dH}_{2} \mathrm{O}\right)$ & $\bullet 2 \mathrm{M} \mathrm{MgCl}_{2}$ \\
- Trios EDTA Sucrose (TES) & $\bullet$ TES/4 & $\bullet$ Acrylamide \\
- Bisacrylamide & $\bullet$ Mercaptoethanol & $\bullet$ Ammonium Persulfate \\
- Hydrochloric acid & $\bullet 500 \mathrm{ml}$ centrifuge bottle, Bottle & $\bullet$ Glycine \\
- TEMED & - Dithiothreitol (DTT) & $\bullet$ Tris base \\
- Phosphate buffered saline (1 xpbs) & - Transfer buffer & $\bullet 3 \%(\mathrm{w} / \mathrm{v}) \mathrm{BSA}$ in PBS \\
- $0.05 \%(\mathrm{v} / \mathrm{v})$ Tween 20 in 1 xpbs (PBS-T) & $\bullet 10 \% \mathrm{SDS}, 100 \mathrm{ml}$ & $\bullet 1.5 \mathrm{M} \mathrm{Tris-HCl} \mathrm{ph} 8.8$
\end{tabular}




\section{Continued}

\begin{tabular}{|c|c|c|}
\hline - 1 M Tris, $\mathrm{pH} 68$ & - Molecular marker & - Mouse anti-his tag \\
\hline - Anti mouse igg HRP & $\begin{array}{l}\text { - Beckman Coulter Avanti J-E centrifuge with } \\
\text { rotor JA-10 }\end{array}$ & - Spectrophotometer \\
\hline - Weight apparatus & - Electrophoresis tank & - Power supply (200 V, 0.6 A) \\
\hline - Western blot cassette & - Transfer tank & - Ice packs \\
\hline - Heat block & - Rocking shaker & - Magnetic stir plate \\
\hline - Shallow tray & - Forceps and scissors & - Magnetic bar \\
\hline - Eppendorf tubes & - Falcon tubes (15 and $50 \mathrm{ml}$ ) & $\begin{array}{l}\text { - Nitrocellulose membrane ( } 0.2 \text { or } 0.45 \mu \mathrm{m} \text { pore size) } \\
\text { store in dark cool place }\end{array}$ \\
\hline - Whatman 3 MM paper & - Gloves & - New Brunswick incubator (New Brunswick, England) \\
\hline - His select solution (Nickle beads) & - Centrifuge & - PD10 column \\
\hline - $0.5 \mathrm{M}$ imidazole in PBS & - NanodropTM & - Clamp \\
\hline
\end{tabular}

\subsection{Expression of Nanobodies in E. coli WK6 Cell Periplasm}

A starter culture of E.coli, transformed with the nanobody gene during cloning step, was obtained from a stock and cultured in Luria broth (LB) containing Ampicillin and Glucose. The culture was grown at $37^{\circ} \mathrm{C}$ overnight while shaking at 200 RPM in a New Brunswick incubator.

The bacteria were inoculated $(1 \mathrm{ml})$ into $330 \mathrm{ml}$ TB supplemented with $330 \mu \mathrm{l}$ $100 \mathrm{mg} / \mathrm{ml}$ ampicillin (Amp) stock, $1.5 \mathrm{ml} 20 \%$ glucose and $330 \mu \mathrm{l} 2 \mathrm{M} \mathrm{MgCl}_{2}$ in a baffled shaker flask. The bacteria were then grown at $37^{\circ} \mathrm{C}$ and $200 \mathrm{RPM}$ till the solution was turbid $\left(\mathrm{OD}_{600}=0.6-0.9\right)$. Then $330 \mu \mathrm{l} 1 \mathrm{M}$ IPTG stock was added per $330 \mathrm{ml}$ TB baffled shaker flask followed by further incubation at $28^{\circ} \mathrm{C}$ and 200 RPM overnight. After overnight expression, turbidity was observed and the culture transferred to a $500 \mathrm{ml}$ centrifuge bottle and pelleted by centrifugation for $8 \mathrm{~min}$ at $8000 \mathrm{RPM}$ and $14^{\circ} \mathrm{C}$ in Beckman Coulter Avanti J-E centrifuge. The supernatant was decanted and the pellet re-suspended in $4 \mathrm{ml}$ Tris-EDTA Sucrose (TES) by pipetting the suspension vigorously. After the suspension was free of cellular clumps, the mixture was incubated for 3 hours on ice while shaking at 200 RPM on a table top shaker. An osmotic shock was given by adding 8 $\mathrm{ml} \mathrm{TES} / 4$ per pellet from $330 \mathrm{ml}$ culture and pipetting vigorously to mix.

This was followed by further incubationon ice while shaking at 200 RPM for 2 hours in a table top shaker. After centrifugation for $30 \mathrm{~min}$ at 8000 RPM in Beckman Coulter Avanti J-E centrifuge, supernatant was pipetted (the periplasmic extract) into $50 \mathrm{ml}$ Falcon tubes without disturbing pellet.

\subsection{Protein Purification (Affinity Chromatography)}

A PD10 column was prepared by loading a frit and washing with $2 \mathrm{ml}$ of PBS. Then, $2 \mathrm{ml}$ of His select slurry (in storage solution) was loaded onto the column and allowed to settle. Flow through was discarded and the packed column washed with $5 \mathrm{ml}$ PBS 1X. The column was then closed to stop flow through. Periplas- 
mic extract (PE) was obtained and $500 \mu \mathrm{l}$ was aliquot into a labeled Eppendorf tube. About $3 \mathrm{ml}$ of PE was added into the closed column and allowed to settle for 10 minutes. The column was then opened and the first flow through collected into a $1.5 \mathrm{ml}$ Eppendorf tube. A further 3 aliquots of the PE ( $3 \mathrm{ml}$ per aliquot) were added into the open column while discarding the flow through. After the last PE addition, the column was washed with 3 aliquots of $12 \mathrm{ml}$ of PBS $1 \mathrm{X}$, with the last wash collected into a $1.5 \mathrm{ml}$ Eppendorf tube. The tube was then closed for elution.

Elution was performed by sequentially adding 3 aliquots of $1 \mathrm{ml}$ of imidazole $(0.5 \mathrm{M})$, the first aliquot was allowed to settle for 10 minutes. Then the column was opened and the elution collected and labelled E1. Then the rest of the aliquots were added sequentially with each aliquot collected in a separate Eppendorf collection tube. These were labeled as E2 and E3. The protein concentration of the imidazole elutions was determined by measuring the $\mathrm{OD}_{280} \mathrm{~nm}$ of the imidazole elutions on the Nanodrop ${ }^{\mathrm{TM}}$. The fraction with the highest $\mathrm{OD}_{280}$ was selected for use in SDS-PAGE and western blot analysis.

\subsection{Analysis of Protein Expression and Purity by SDS PAGE and Western Blot}

\subsubsection{Analysis by SDS-PAGE}

A two (2) Glass plates (Biorad, USA) for polyacrylamide gel electrophoresis (PAGE) were assembled in parallel and a $12 \%$ running gel for each was prepared $(100 \mu \mathrm{l}$

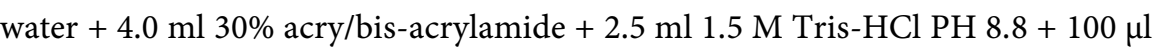
10\% SDS). $5 \mu \mathrm{l}$ TEMED and Ammonium Per sulfate (APS) were then added last to the mix, and the mixture inverted twice to mix, avoiding bubble formation. Using P1000 micropipette, the gel was dispensed between the glass plate assemblies until about $0.5 \mathrm{~cm}$ below the level where teeth of comb would reach. Then about a $2 \mathrm{~mm}$ of layer of water was poured on top of the running gel (to keep the surface of gel flat and prevent oxidation of gel surface) and polymerization allowed to occur for 30 minutes.

The water covering the separating gel was poured off and $4 \%$ stacking gel (3.645 $\mathrm{ml}$ water $+0.650 \mathrm{ml} \mathrm{30 \%}$ acry/bis-acrylamide $+0.650 \mathrm{ml} 1.5 \mathrm{M}$ Tris- $\mathrm{HCl}$ PH $8.8+50 \mu 10 \%$ SDS $+5 \mu$ TEMED $+25 \mu \mathrm{l} 10 \%$ Ammonium Per sulfate(APS) was prepared as described before and added ontop separating gel until solution reached top of the front plate. Then a comb was inserted into the gel sandwich until bottom of teeth reached top of front plate and the gel allowed to polymerize for 30 minutes. The comb was removed carefully and gel placed into electrophoresis chamber onto the electrode assembly. Then buffer was added to the inner and outer reservoir until the gel was immersed. $10 \mu \mathrm{l}$ sample proteins (marker, positive control, PE, E, FT, and W) were mixed with $5 \mu \mathrm{l} 5 \mathrm{x}$ sample buffer in an Eppendorftube and heated for 5 minute at $100^{\circ} \mathrm{C}$ on a heating block. The sample solutions were then spun for 1minute in a micro-centrifuge to collect at the bottom of the tube. All samples were introduced in parallel into the 
wells on the gel (Marker + positive control (with known nanobody) $+\mathrm{PE}+\mathrm{E}+$ FT $+\mathrm{W}$ ) and plugs attached to proper electrodes. The assembly was allowed to run at 150 volts for 1 hour.

One gel was then transferred into a container and stained with Coomassie blue for 15 minutes with agitation and de-stained with Coomassie de-stain for 30 minutes with agitation. After de-staining for about 3 hours, the gel was scanned for interpretation.

\subsubsection{Confirming Nanobody Protein Expression by Western Blot}

The second gel from the SDS-PAGE was used. A nitrocellulose membrane (6 $\mathrm{cm}$ ) was cutand immersed to wet in transfer buffer $(30 \mathrm{ml})$. Using a shallow tray with transfer buffer, the transfer cassette was opened and a wetted sheet of Whatman paper $3 \mathrm{MM}$ paper was placed on a well-soaked filter pad on the black panel of the transfer cassette. The gel is placed on the wet filter paper on black side of the assembly. The gel was wet and a wetted sheet of nitrocellulose was laid carefully on top, beginning from one side (to remove air bubbles). A second well-soaked fiber pad was placed over the nitrocellulose and a small pipette was rolled over the sandwich to remove any air bubbles. The transfer cassette was closed and slid into the electrode insert in the buffer tank, keeping the black side of the cassette on the same side as the black panel of the electrode assembly. The buffer chamber was rinsed with $\mathrm{dH}_{2} \mathrm{O}$, an electrode inserted and small stir bar inserted into buffer chamber, and transfer buffer was added until half full. Then frozen cooling unit was inserted. The buffer tank was filled with transfer buffer and the entire Trans-blot apparatus was placed on a magnetic stir plate for stirring. The power supply was set to $100 \mathrm{~V}$ and transferred for $1 \mathrm{~h}$.

Immuno-detection with Horse Raddish peroxidise conjugate was then performed. Briefly, the nitrocellulose membrane was removed from transfer apparatus into a small container. Unbound sites on the membrane blocked with 20 $\mathrm{ml} 3 \%(\mathrm{w} / \mathrm{v}) \mathrm{BSA}$ in PBS and the filter was gently rocked for 45 minutes. Blocking solution was poured off and the membrane rinsed briefly (3X) with $0.05 \%$ $(\mathrm{v} / \mathrm{v})$ Tween 20 in 1 XPBS (PBS-T). Then the membrane was flooded with $15 \mathrm{ml}$ of the first antibody (mouse anti-his IgG antibody) diluted (1/1000) in 3\% (w/v) BSA in PBS and rocked gently for 45 minutes. The first antibody solution was poured off from membrane and the membrane washed (3X) with PBS-T. After pouring off $\mathrm{PBS}-\mathrm{T}$, the membrane was then flooded with $15 \mathrm{ml}$ of a second antibody (anti-mouse IgG HRP) diluted (1/1000) 3\% (w/v) BSA and rocked gently for 45 minutes. The second antibody solution was poured off from membrane and the membrane rinsed (3X) with PBS-T. A developing reagent for HRP was prepared and added on the membrane. The membrane was gently rocked while monitoring development (15 minutes) and development was stopped by washing with distilled $\mathrm{H}_{2} \mathrm{O}$. The membrane was dried with adsorbent paper and stored (wrapped with aluminium foil). Then scan of the membrane was made within a day for interpretation. 


\section{Results}

Upon elution with imidazole, the concentrations observed using the $\mathrm{OD}_{280} \mathrm{~nm}$ of the eluted fractions EI, E2 and E3 were observed to be $0.42 \mu \mathrm{g} / \mathrm{ml}, 0.13 \mu \mathrm{g} / \mathrm{ml}$ and $-0.46 \mu \mathrm{g} / \mathrm{ml}$ respectively. The gel scan photograph is shown below.

After scanning the SDS-PAGE gel, faint bands were noted on the gel aligning to the position at which the control Nanobody marker was present (marked with black arrow). This corresponded to the region between molecular marker 15 $\mathrm{kDa}$ and $10 \mathrm{kDa}$. Thus the protein's size was determined to be approximately 8 $\mathrm{kDa}$. This was confirmed using the formula (Figure 2).

Table 1 below shows the relative distance in units of migration of the marker bands from the edge of the photograph, taken as the start point for migration.

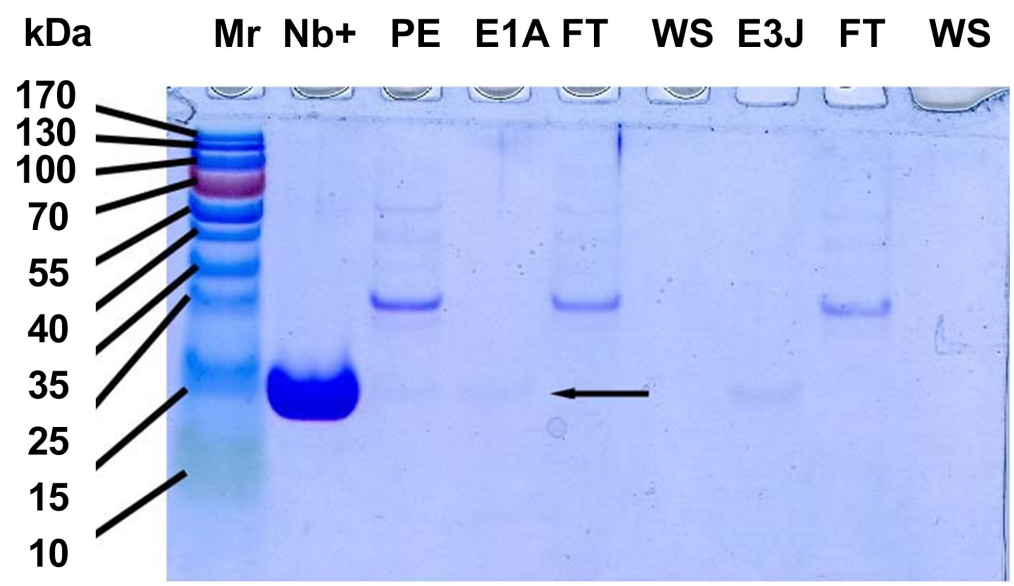

Figure 2. Sodium Dodecyl Sulfate Polyacrylamide Gel Electrophoresis (SDSPAGE) based gel alignment to determine its concentration at $\mathrm{OD}_{280} \mathrm{~nm}$.

Table 1. The relative distance in units of migration of the marker bands.

\begin{tabular}{cccc}
\hline Mr weight & Distance & Log Mr & Rf \\
\hline 10 & 24 & 1 & 0.923077 \\
15 & 18 & 1.176091 & 0.692308 \\
25 & 13 & 1.39794 & 0.5 \\
35 & 11 & 1.544068 & 0.423077 \\
40 & 9 & 1.60206 & 0.346154 \\
55 & 8 & 1.740363 & 0.307692 \\
70 & 6 & 1.845098 & 0.230769 \\
100 & 5 & 2 & 0.192308 \\
130 & 4 & 2.113943 & 0.153846 \\
170 & 3 & 2.230449 & 0.115385 \\
\hline
\end{tabular}




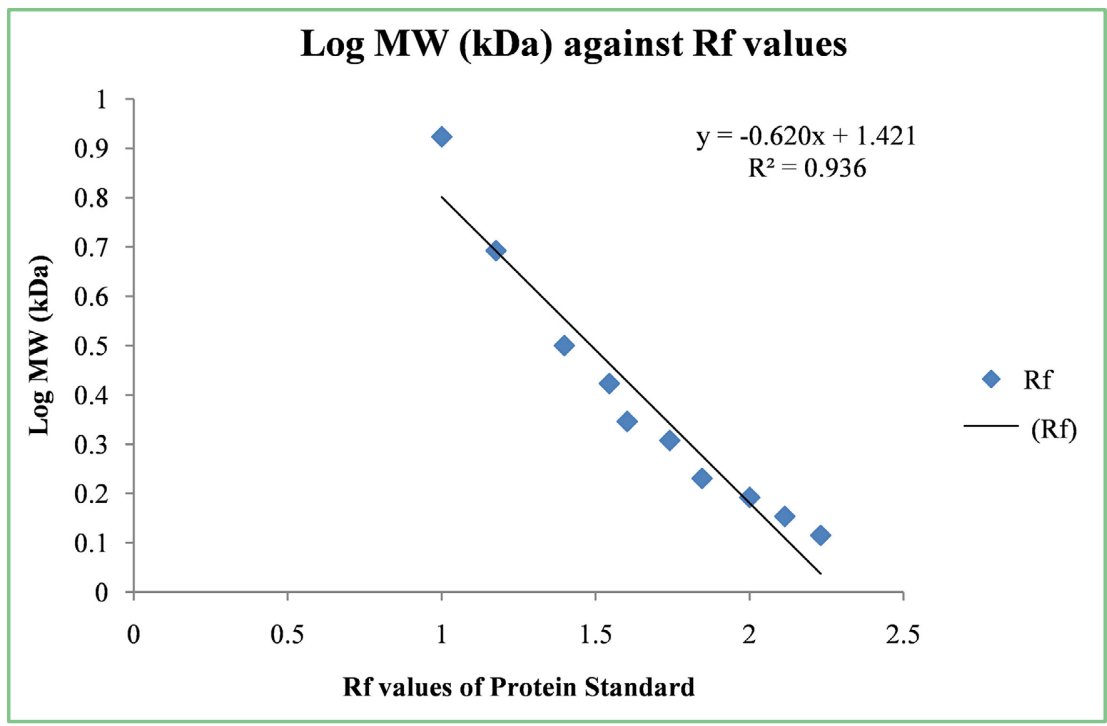

Given the equation

Figure 3. Molecular size determination.

$$
y=-0.6206 x+1.4217
$$

we can calculate the expected molecular size of the unknown protein bands (Figure 4).

The band of unknown protein was estimated have migrated up to 22 units from the wells, thus their relative distance travelled (Table 1 ) is approximately 0.846154 . Replacing $X$ in the equation above; $y=(-0.6206 \times 0.846154)+1.4217$, we get 2.7923. This gives an Antilog of $7.88 \mathrm{kDa}$. This is the calculated molecular size of our band.

The SDS-PAGE gel reading was confirmed using Western blot analysis. The photograph illustrates the specific binding of the mouse Anti-His antibody to the Histidine tag of the Nanobody (indicated by black arrow) (Figure 4).

\section{Discussion}

The results presented in this article indicate the expression of a recombinant nanobody gene in a $E$. coli WK6 bacterial system. The $E$. coli WK6 $\Delta$ (lac-proAB)galEstrA [F'lacIq lacZ $\triangle \mathrm{M} 15$ proAB+] is a bacterial expression system that has been utilized for inducible expression of a variety of plasmids It has a high replication rate and has been shown to be highly amenable to physical and chemical manipulation. In this context, the $E$. coli WK6 has been used in various studies for the production of the nanobody gene [5] [6] and [14].

The pHEN6(C) plasmid is a genetically engineered plasmid designed to enable successful expression of the Nanobody gene. The pHEN6(C) contains a multiple cloning site (MCS) an Ampicillin resistance $(a m p R)$ gene, an origin of replication (ori), an inducibleLacZ promoter, a PelB signal and a hexahistidine tag [4] [15]. The nanobody gene was inserted into the vector via the MCS site after prior restriction digestion of both the vector and recombinant gene with Eco911 and Pst1. The vector was then inserted by transformation into the E. coli WK6 cells 


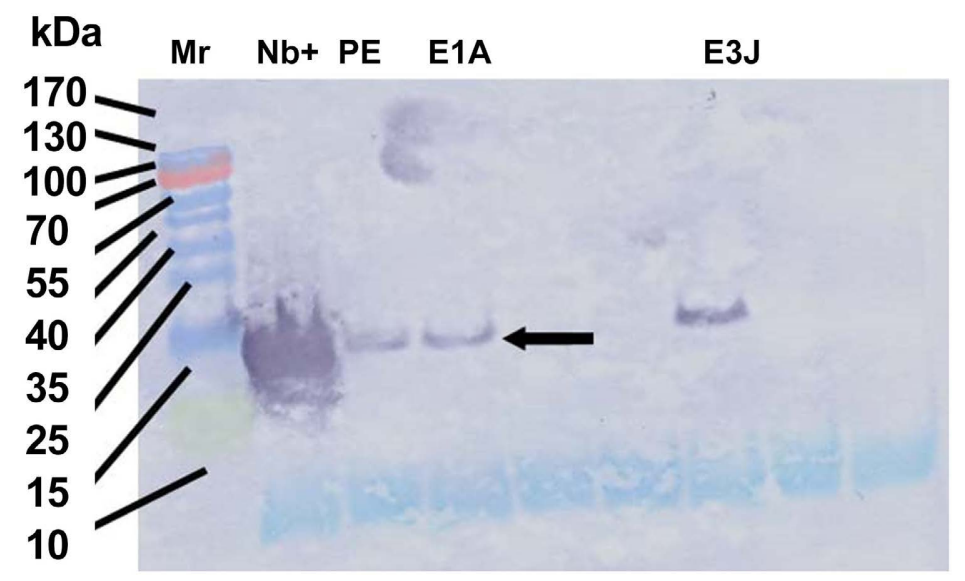

Figure 4. The photograph illustrates the specific binding of the mouse. $\mathrm{Mr}=$ Molecular weight, $\mathrm{Nb}+=$ Nanobody, PE, E1A and E3J are samples.

as described previously [4] [5]. Of interest in this study was the use of the ampicillin resistance gene $(a m p R)$ that enabled the selective growth in nutrient broth (LB ampicillin media). Induction of the LacZ promoter undertaken using $\beta$-D1-thiogalactopyranoside (IPTG) enabled the over-expression of the nanobody gene placed downstream of this promoter. The expressed protein was then transported to the periplasmic region for proper folding into its functional form as described by previous studies [16]. Proper folding of a protein within the bacterial cell's cytoplasm is a challenge due to the crowded conditions. Thus most recombinant proteins are engineered with a secretion signal (in this case, the PelB signal) which allows for proper folding of the expressed protein, thus enabling over expression and preventing the formation of inclusion bodies (insoluble masses of aggregated proteins) [16].

Once expression is done, the next challenge facing the investigator is obtaining the recombinant protein in a more or less pure fashion without degradation by the proteolytic enzymes in the cell. In this study, the bacterial cells were osmotically shocked by incubating with Tris EDTA sucrose (TES), followed by further incubation with a dilute TES (diluted 4 times with distilled $\mathrm{H}_{2} \mathrm{O}$ ). This method allows the rupture of the bacterial cells without mechanical stress that would rupture the lsysosomes hence degrading any and all protein content via proteolysis. The EDTA contained in the TES further enhanced this inhibition effect of proteolysis, thus yielding high protein content after osmotic shock. It has been reported that EDTA possesses some metalloprotease inhibitory activity [17].

Purifying the protein was achieved in this study by utilizing the hexahistidine tag engineered into the vector downstream of the gene. This tag is translated into a hexahistidine tag at the $\mathrm{C}$ terminal of the recombinant nanobody protein without interfering with the normal protein folding. The hexahistidine tag, being highly positively charged, allows for purification via nickel affinity purification, a type of metal affinity purification (IMAC) [7]. Purified protein can then be eluted by changing the $\mathrm{pH}$ of the nickel column such that the histidine residues 
lose their positive charge and flow through the column.

Analysis of the purified protein via SDS-PAGE (reducing polyacrylamide gel electrophoresis) revealed a faint band at the position corresponding to $15 \mathrm{kDa}$ protein marker (Figure 2). This indicated the presence of a protein with approximately the correct molecular weight (Figure 3 ). The faintness of the bands was probably indicative of a low protein concentration being loaded onto the gel. This can be corrected by checking the concentration of the protein being loaded onto the column. If possible, equal amounts of protein should be loaded onto the column to enable band visualization after staining.

The nanobody protein expression was then analyzed further with western blotting. This is a more specific method than the coomasie blue staining as it is specific to the protein being detected. The results show a strong signal at the region corresponding to the $15 \mathrm{kDa}$ marker indicating presence of the Nanobody gene (Figure 4). This was taken as further confirmation of the protein expression from the bacterial cells.

\section{Conclusion and Recommendation}

There are many methods and protocols to determine the concentration of Proteins. Of these, SDS PAGE, Western Blotting and Affinity chromatography are the most common and many labs are routinely have been using for analysis of protein expression and purity. These days, pHEN6 has been used to express protein due to the fact that this vector contains a multiple cloning site (MCS) for the action of restriction enzymes, contains sites which enable restriction digestion and also contains an Ampicillin resistance $(\operatorname{ampR})$ gene which enables antibiotic resistance driven selection for successfully transformed colonies from naive bacteria. Similar works should be conducted and compared in order to see the relevance of these techniques for large scale protein pharmaceutical protein production and determination of its concentration in advance of the technology today.

\section{Conflicts of Interest}

The author declares no conflicts of interest regarding the publication of this paper.

\section{References}

[1] Muyldermans, S. (2013) Nanobodies: Natural Single-Domain Antibodies. Annual Review of Biochemistry, 82, 775-797. https://doi.org/10.1146/annurev-biochem-063011-092449

[2] Baneyx, F. (1999) Recombinant Protein Expression in Escherichia coli. Current Opinion in Biotechnology, 10, 411-421. https://doi.org/10.1016/S0958-1669(99)00003-8

[3] Stoyanov, J.V. and Brown, N.L. (2003) The Escherichia coli Copper-Responsivecopa Promoter Is Activated by Gold. Journal of Biological Chemistry, 278, 1407-1410. https://doi.org/10.1074/jbc.C200580200

[4] Conrath, K.E., Lauwereys, M., Galleni, M., Matagne, A., Frere, J.-M., Kinne, J., 
Wyns, L. and Muyldermans, S. (2001) Beta-Lactamase Inhibitors Derived from Single-Domain Antibody Fragments Elicited in the Camelidae. Antimicrobial Agents and Chemotherapy, 45, 2807-2812.

https://doi.org/10.1128/AAC.45.10.2807-2812.2001

[5] Baral, T.N., Magez, S., Stijlemans, B., Conrath, K., Vanhollebeke, B., Pays, E., Muyldermans, S. and De Baetselier, P. (2006) Experimental Therapy of African Trypanosomiasis with a Nanobody-Conjugated Human Trypanolytic Factor. Nature Medicine, 12, 580-584. https://doi.org/10.1038/nm1395

[6] Abderrazek, R.B., Hmila, I., Vincke, C., Benlasfar, Z., Pellis, M., Dabbek, H., Saerens, D., El Ayeb, M., Muyldermans, S. and Bouhaouala-Zahar, B. (2009) Identification of Potent Nanobodies to Neutralize the Most Poisonous Polypeptide from Scorpion Venom. Biochemical Journal, 424, 263-272.

https://doi.org/10.1042/BJ20090697

[7] Gu, J., Stephenson, C.G. and Iadarola, M.J. (1994) Recombinant Proteins Attached to a Nickel-NTA Column: Use in Affinity Purification of Antibodies. BioTechniques, 17, 257-261.

[8] Ghahroudi, M.A., Desmyter, A., Wyns, L., Hamers, R. and Muyldermans, S. (1997) Selection and Identification of Single Domain Antibody Fragments from Camel Heavy-Chain Antibodies. FEBS Letters, 414, 521-526.

https://doi.org/10.1016/S0014-5793(97)01062-4

[9] Muyldermans, S., Baral, T.N., Retamozzo, V.C., De Baetselier, P., De Genst, E., Kinne, J., Leonhardt, H., Magez, S., Nguyen, V.K., Revets, H., Rothbauer, U., Stijlemans, B., Tillib, S., Wernery, U., Wyns, L., Hassanzadeh-Ghassabeh, G. and Saerens, D. (2009) Camelidimmunoglobulins and Nanobody Technology. Veterinary Immunology and Immunopathology, 128, 178-183. https://doi.org/10.1016/j.vetimm.2008.10.299

[10] Shapiro, A.L., Viñuela, E. and Maizel Jr., J.V. (1967) Molecular Weight Estimation of Polypeptide Chains by Electrophoresis in SDS-Polyacrylamide Gels. Biochemical and Biophysical Research Communications, 28, 815-820.

https://doi.org/10.1016/0006-291X(67)90391-9

[11] Chial, H.J., Thompson, H.B. and Splittgerber, A.G. (1993) A Spectral Study of the Charge Forms of Coomassie Blue G. Analytical Biochemistry, 209, 258-266. https://doi.org/10.1006/abio.1993.1117

[12] Compton, S.J. and Jones, C.G. (1985) Mechanism of Dye Response and Interference in the Bradford Protein Assay. Analytical Biochemistry, 151, 369-374. https://doi.org/10.1016/0003-2697(85)90190-3

[13] Towbin, H., Staehelin, T. and Gordon, J. (1979) Electrophoretic Transfer of Proteins from Polyacrylamide Gels to Nitrocellulose Sheets: Procedure and Some Applications. Proceedings of the National Academy of Sciences of the United States of America, 76, 4350-4354. https://doi.org/10.1073/pnas.76.9.4350

[14] Primorose, S.B. and Twyman, R.M. (2006) Principles of Gene Manipulation and Genomics. 7th Edition. Blackwell Publishing, Malden.

[15] Saerens, D. (2010) Isolation and Optimization of Camelid Single-Domain Antibodies: Dirk Saerens' Work on Nanobodies. World Journal of Biological Chemistry, 1, 235-238. https://doi.org/10.4331/wjbc.v1.i7.235

[16] Baneyx, F. and Mujacic, M. (2004) Recombinant Protein Folding and Misfolding in Escherichia coli. Nature Biotechnology, 22, 1399-1408. https://doi.org/10.1038/nbt1029

[17] Bernkop-Schnürch, A. and Scerbe-Saiko, A. (1998) Synthesis and in Vitro Evalua- 
tion of Chitosan-EDTA-Protease-Inhibitor Conjugates Which Might Be Useful in Oral Delivery of Peptides and Proteins. Pharmaceutical Research, 15, 263-269.

https://doi.org/10.1023/A:1011970703087 